\title{
Eksperimental Studi Performance Organic Rankine Cycle(ORC) Menggunakan Fluida Kerja r245fa Dengan Sumber Panas di Evaporator $120^{\circ} \mathrm{C}$
}

\author{
Mochamad Denny Surindra \\ Jurusan Teknik Mesin Politeknik Negeri Semarang \\ Jl. Prof. H. Sudarto, S.H., Tembalang,Semarang \\ E-mail: dennysurindra@polines.ac.id \\ Diterima: 04-12-2019; Direvisi: 20-12-2019; Dipublikasi: 31-12-2019
}

\begin{abstract}
Abstrak
Energi panas yang terbuang dari industri dan sumber energi terbarukan di seluruh dunia dapat digunakan untuk menghasilkan tenaga sehingga mengurangi konsumsi bahan bakar fosil. Salah satu teknologiny aadalah Organic Rankine Cycle (ORC) dengan fluida kerja R245fa. Refrigerant R245fa dengan laju aliran massa 0,2 kg/s menghasilkan perpindahan energi panas di kondensor43,35 kJ/s sedangkan di evaporator sebesar 50,094 kJ/s. Daya poros pompa yang dihasilkan adalah maksimum sebesar $0,204 \mathrm{~kJ} / \mathrm{s}$ dan lebih kecil jika dibandingkan dengan daya output sroll expander yang mencapai $5,022 \mathrm{~kJ} / \mathrm{s}$. Sehingga daya yang dihasilkan lebih besar daripada daya yang dibutuhkan dan effisiensi thermal ORC system yang tertinggi terjadi pada saat laju aliran massa $0,2 \mathrm{~kg} / \mathrm{s}$ sebesar $12,3 \%$.
\end{abstract}

Kata kunci: Organic Rankine Cycle; ORC; R245fa; Evaporator.

\begin{abstract}
Wasted heat energy from industries and renewable energy sources throughout the world can be used to produce power, thereby reducing fossil fuel consumption. One of the technologies used is Organic Rankine Cycle (ORC) with $R 245 f a$ working fluid. R245fa refrigerant with a mass flow rate of $0.2 \mathrm{~kg} / \mathrm{s}$ produces heat energy transfer in the condenser $43.35 \mathrm{~kJ} / \mathrm{s}$, while in the evaporator is $50.094 \mathrm{~kJ} / \mathrm{s}$. The maximum pump shaft power is $0.204 \mathrm{~kJ} / \mathrm{s}$ where this value is smaller than the sroll expander output power which reaches 5,022 kJ/s. So that the power generated is greater than the power needed and the highest thermal efficiency ORC system occurs when the mass flow rate of 0.2 $\mathrm{kg} / \mathrm{s}$ is $12.3 \%$.
\end{abstract}

Keyword: Organic Rankine Cycle; ORC; R245fa; Evaporator.

\section{Pendahuluan}

Organic Rankine cycle (ORC) merupakan teknologi yang menjanjikan untuk masa depan karena beroperasi dengan temperature rendah dengan memanfaatkan energy panas yang terbuang. Teknologi ini menggunakan struktur yang sederhana, keandalan tinggi, perawatan mudah, serta potensi yang lebih baik dalam mengubah panas buang bertemperature rendah menjadi listrik. ORC sudah banyak diaplikasikan dalam pemanfaatan berbagai sumber panas, seperti panas limbah industri, energi matahari, energi panas bumi, energi biomassa, Ocean Thermal Energy Conversion (OTEC), diesel engine, dan turbin gas [1]. Dari aspek analisis teoretis, para peneliti banyak yang melakukan research tentang pemilihan fluida kerja, pengembangan proses ekspansi, konfigurasi ORC, modifikasi sitem dan optimalisasi dengan multi-objektif [2].

Karakteristik operasi expander yang bekerja sebagai turbine pada teknologi ORC memiliki pengaruh yang signifikan pada kinerja sistem keseluruhan, dengan demikian banyak peneliti mencurahkan upaya pada pengembangan expander. Berbagai macam expander telah diuji, seperti opened drive scroll type expander [3], single state axial flow turbine [4], radial turbin [5], screw expander [6], rolling-piston expander [7]. Efisiensi isentropik maksimum expander berkisar antara 50-80\% dan dengan pertimbangan secara mekanis diperlukan untuk memilih expander yang sesuai dengan prototype ORC. 
Fluida kerja yang digunakan juga mempengaruhi karakteristik operasi prototype ORC system. Quoilin et al. [8] mengusulkan R245fa sebagai fluida kerja untuk menganalisi data dinamis pada eksperimen yang dilakukannya. Sedangkan Pu et al. [9] mempelajari efek dari tekanan penguapan, penurunan tekanan dan laju aliran massa pada kinerja sistem secara keseluruhan menggunakan R245fa dan HFE7100, adapun hasilnya menunjukkan bahwa R245fa menghasilkan output daya listrik yang lebih baik HFE7100. Guillaume et al. [10] mengaplikasikan ORC untuk memanfaatkan gas buang mesin truk dan fokus pada uji komparatif menggunakan R245fa dan R1233zd. Hu et al. [11] mempelajari pengaruh tingkat superheat pada prototipe ORC dengan kapasitas $500 \mathrm{~W}$ menggunakan fluida kerja R245fa. Ziviani et al. [12] membahas karakteristik operasi uji ORC dengan siklus regeneratif skala kecil menggunakan R245fa dan SES36, menyatakan bahwa SES36 menghasilkan rasio tekanan yang relatif lebih tinggi dan efisiensi isentropik expander keseluruhan 64,7\%. Sung et al. [13] melakukan uji operasi prototipe ORC $200 \mathrm{~kW}$ menggunakan R245fa untuk memanfaatkan limbah panas dari gas buang di pabrik pengolahan baja, dan menghasilkan data efisiensi termal 9,6\% dan output daya bersih $177,4 \mathrm{~kW}$.

Tinjauan literatur sebelumnya mengungkapkan bahwa beberapa eksperimental investigasi prototipe ORC skala kecil telah banyak dilakukan. Namun, beberapa dari mereka secara eksperimental menyelidiki pengaruh strategi operasi yang berbeda-beda. Karena itu, dalam pekerjaan yang ingin diungkap sekarang berfokus pada karakteristik operasi ORC yang prototipenya telah dibangun di laboratarium. Fluida kerja yang digunakan adalah R245fa karena refrigerant tersebut mempunyai karakter yang tidak meledak dan tidak mudah terbakar.

\section{Material dan metodologi}

Loop ORC terdiri dari empat komponen utama: pompa piston, evaporator, scroll expander, dan kondensor seperti yang terlihat dalam Gambar 1.

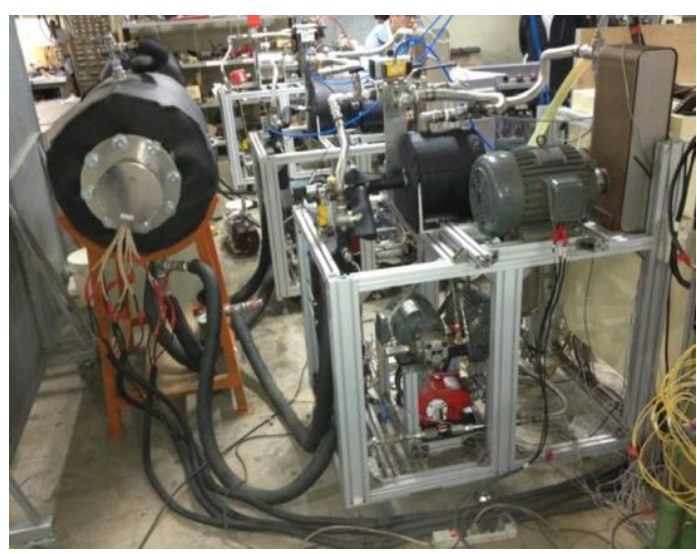

Gambar 1. Prototipe ORC system

Pompa memasok fluida kerja yang berada pada fase cair ke evaporator, dimana fluida kerja dipanaskan dan diuapkan oleh oli pelumas yang dipanaskan dan difungdikan sebagai sumber panas. Uap tekanan tinggi mengalir ke expander dan energy uap superheat diekspansikan menjadi energy kinetic. Uap tekanan rendah keluar expander dan dialirkan ke kondensor untuk merubah menjadi fase cair dengan memanfaatkan air dingin dari chiller. Cairan tersedia di outlet kondensor, dan kemudian dipompa kembali ke evaporator dan siklus baru dimulai. 
Daya poros pompa dapat dihitung dengan tekanan dan temperature yang diukur, sementara konsumsi daya diukur dengan konverter frekuensi pompa. Daya poros pompa (Wp,pump) dapat diekpresikan dengan persamaan sebagai berikut:

$$
W_{p}=\dot{m}\left(h_{3}-h_{2}\right)
$$

Uap yang mengalami kompresi mengalir melalui evaporator dan keluar pada kondisi superheat. Selama proses infiltrasi panas dari sisi inlet ke sisi outlet, oli yang panas menginfiltrasi dan memberikan energi panas ke dalam fluida kerja. Total laju perpindahan panas (Qevap) dari sumber panas ke fluida kerja dalam evaporator ditunjukkan dalam persamaan sebagai berikut:

$$
Q_{\text {evap }}=\dot{m}\left(h_{3}-h_{2}\right)
$$

Uap superheat pada sisi keluar evaporator mengalir ke scroll expander dimana uap superheat tersebut berekspansi memberikan energy dan menghasilkan daya keluaran dengan memutar poros. Tekanan dan penurunan suhu selama proses ini kemudian dilepaskan ke sisi keluar scroll expander. Dengan mengabaikan aliran perpindahan panas masuk dan mengalir keluar ke sekitarnya, daya output scroll expander (Wt) dapat ditulis sebagai:

$$
W_{\text {turbine }}=\dot{m}\left(h_{3}-h_{4}\right)
$$

Kondensor memfasilitasi perpindahan panas dari uap ke air pendingin yang mengalir dalam saluran terpisah. Menurut prinsip keseimbangan massa dan energi untuk volume yang dikendalikan pada kondensor, panas keluaran dapat ditulis sebagai berikut ini:

$$
Q_{\text {cond }}=\dot{m}\left(h_{1}-h_{4}\right)
$$

Efisiensi termal dapat direpresentasikan sebagai rasio antara output total terhadap daya input dan laju transfer panas. Efisiensi termal dapat digambarkan sebagai berikut ini:

$$
\begin{gathered}
\eta=\frac{W_{\text {turb }} / \dot{m}-W_{\text {pump }} / \dot{m}}{Q_{\text {in }} / \dot{m}} \\
\eta=\frac{\left(h_{3}-h_{4}\right)-\left(h_{2}-h_{1}\right)}{h_{3}-h_{2}}
\end{gathered}
$$

Karena energi input dan work output sama dengan total energi panas yang beroperasi, maka efisiensi termal dapat juga diekspresikan sebagai berikut ini: 
$\eta=\frac{Q_{\text {in }} / \dot{m}}{Q_{\text {in }} /_{\dot{m}}}$

$\eta=1-\frac{Q_{\text {out }} / \dot{m}}{Q_{\text {in }} / \dot{m}}$

$\eta=1-\frac{\left(h_{4}-h_{1}\right)}{h_{3}-h_{2}}$

\section{Hasil dan pembahasan}

Untuk mengetahui performance fluida kerja R245fa yang bekerja pada sumber panas yang telah ditetapkan sebesar 1200C, maka laju aliran massa diubah-ubah dengan mengatur frekuensi pompa. Dari eksperimen data yang diperoleh selama tes pada kondisi operasi steady-state, keadaan termodinamika (suhu dan tekanan) dan data terukur, terperinci karakteristik operasi untuk fluida kerja murni dan campuran adalah dibahas, sementara penyelidikan lebih lanjut tentang kinerja sistem akhirnya terbuka.

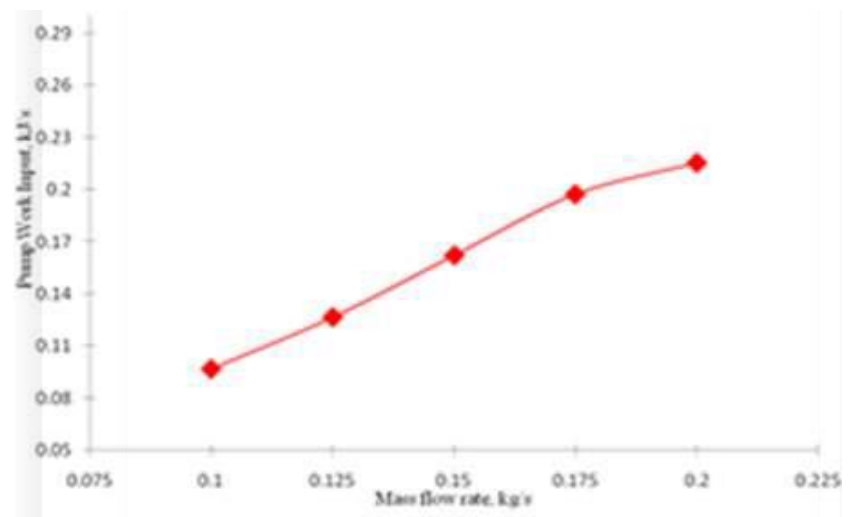

Gambar 2. Perubahan laju aliran massa terhadap daya poros pompa

Gambar 2 menunjukan peningkatan daya poros pompa seiring dengan penambahan laju aliran massa fluida kerja. Hal ini terkait dengan penambahan frekuensi pompa untuk menambah kecepatan pompa. Semakin cepat pompa bekerja maka semakin besar laju aliran massa fluida kerja R245fa, dan semakin besar daya poros pompa yang dibangkitkan untuk mengalirkan fluida kerja. Daya poros maksimum tercatat sebesar $0,204 \mathrm{~kJ} / \mathrm{s}$ pada saat laju aliran massa $0,2 \mathrm{~kg} / \mathrm{s}$, sedangkan daya poros minimum sebesar $0,109 \mathrm{~kJ} / \mathrm{s}$ dengan laju aliran massa sebesar $0,1 \mathrm{~kg} / \mathrm{s}$.

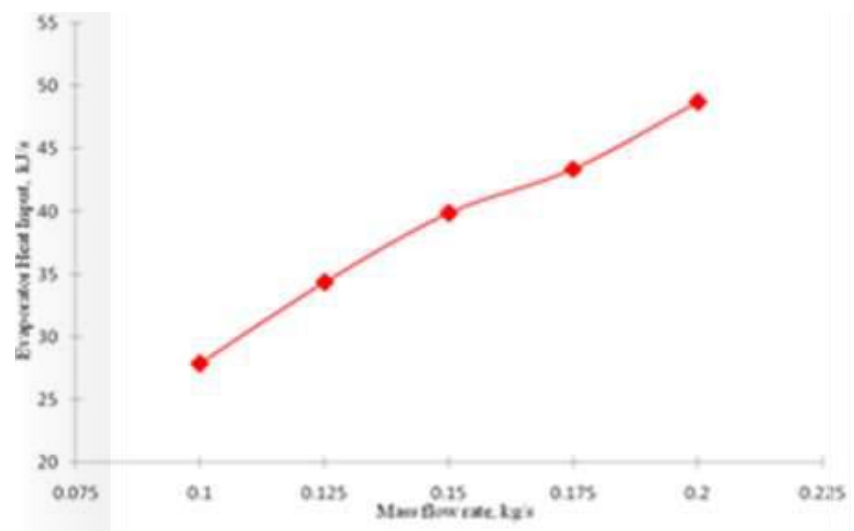

Gambar 3. Perubahan laju aliran massa terhadap Laju perpindahan panas Evaporator 
Laju perpindahan panas Evaporator mengalami peningkatan yang signifikan ketika laju aliran massa fluida kerja berubah seperti yang ditunjukan dalam gambar 2. Evaporator mendapat sumber energi panas dari oli yang dipanaskan menggunakan heater dan dijaga konstan pada temperatur 1200C di titik masuk Evaporator. Laju aliran panas yang tercatat antara 30-50,094 kJ/s dengan enthalpi sebesar 233,91-478,1 kJ/kg.K.

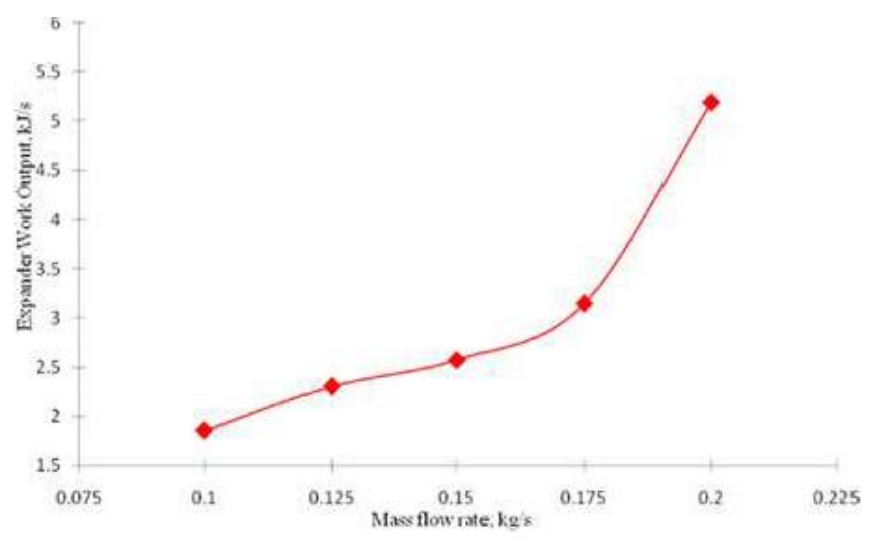

Gambar 4. Perubahan laju aliran massa terhadap daya output Scroll expander

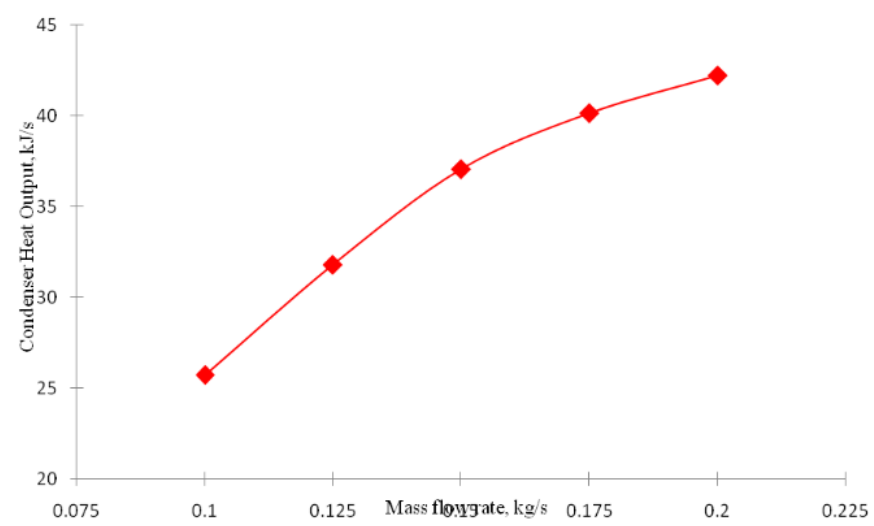

Gambar 5. Perubahan laju aliran masa terhadap Laju perpindahan panas Kondensor

Scroll expander yang berfungsi sebagai tempat untuk menyerap energi uap superheat yang berekspansi sebagai daya output mengalami kenaikan yang melandai dan pada laju aliran massa $0,175 \mathrm{~kg} / \mathrm{s}$ meningkat tajam sampai berakhirnya eksperiment, seperti yang ditunjukan dalam gambar 4. Daya output sroll expander terkecil sebesar 1,6 kJ/s dan terbesar mencapai 5,022 kJ/s. Pada saat menghasilkan daya output maksimum, fluida kerja mengalir dengan laju aliran massa $0,2 \mathrm{~kg} / \mathrm{s}$, dimana pada sisi masuk scroll expander tercatat tekanan berkisar 11,5 bar dan temperature sebesar 1040C, sedangkan pada sisi keluarnya mempunyai tekanan sekitar 3 bar dan temperature 560C.

Setelah mengalami ekspansi, fluida kerja R245fa mengalir masuk ke dalam kondensor untuk melepaskan sisa energi panas ke air pendingin dan fluida kerja berkondensasi menjadi fase cair kembali. Pada gambar 5 menunjukan energi panas yang dilepaskan ke air pendingin meningkat tajam seiring dengan bertambahnya laju aliran massa fluida kerja. Temperature air pendingin berasal dari chiller air conditioning dengan temperature berkisar 260C dan keluar dari kondensor berkisar 280C. Laju perpindahan panas yang dihasilkan terendah adalah $26 \mathrm{~kJ} / \mathrm{s}$ sedangkan yang tersesar mencapai $43,35 \mathrm{~kJ} / \mathrm{s}$. 


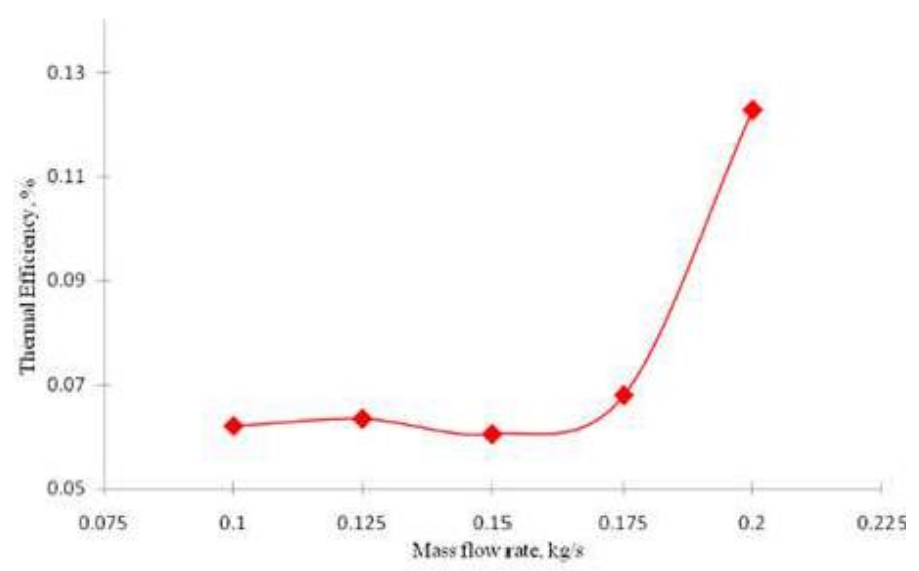

Gambar 6. Perubahan laju aliran massa terhadap Effisiensi thermal

Performance sistem ORC yang telah dibangun ditunjukan dalam gambar 6, dimana effisiensi thermal tidak ada perubahan yang signifikan pada saat laju aliran masa fluida kerja $0,1-0,5 \mathrm{~kg} / \mathrm{s}$, tetapi pada saat laju aliran massa 0,175 $0,2 \mathrm{~kg} / \mathrm{s}$ terjadi peningkatan yang sangat signifikan. Effisiensi thermal yang dihasilkan pada saat landai sebesar 6,1-6,3 $\%$ sedangkan pada saat meningkat secara signifikant sebesar 6,8 \% dan maksimum 12,3\%.

\section{Kesimpulan}

ORC system yang dibangun dapat bekerja dengan baik dan refrigerant R245fa mempunyai kinerja yang bisa diaplikasikan untuk ORC system. Laju aliran massa yang direkomendasikan untuk beroperasi menggunakan ORC system yang dibangun tertinggi sebesar $0,2 \mathrm{~kg} / \mathrm{s}$, kalau melebihi harga tersebut akan menghasilkan tekanan yang cukup besar dan membuat kebocoran di system. Perpindahan energy panas di kondensor adalah 43,35 kJ/s lebih besar dari pada di evaporator yang tercatat sebesar $50,094 \mathrm{~kJ} / \mathrm{s}$. Daya poros pompa maksimum sebesar 0,204 kJ/s sedangkan daya output sroll expander yang terbesar hanya mencapai 5,022 kJ/s. Hal ini menunjukan bahwa ORC system membutuhkan energi untuk menggerakan pompa jauh lebih sedikit dibandingkan dengan energi yang dihasilkan oleh scroll expander. Effisiensi thermal ORC system yang tertinggi terjadi pada saat laju aliran massa $0,2 \mathrm{~kg} / \mathrm{s}$ sebesar $12,3 \%$.

\section{Daftar Pustaka}

[1] Agus, dkk. PengendalianTinggi Muka Cairan Berbasis fuzzy (fuzzy Based Liquid Height Controlling). FakultasTeknik. Universitas Semarang.

[2] Surindra M.D., Caesarendra W., Prasetyo T., Mahlia T.M.I., Taufik. Comparison of the utilization of 1100C and $1200 \mathrm{C}$ heat source in a geothermal energy system using Organic Rankine Cycle (ORC) with R245fa, R123, and mixed-ratio fluids as working fluids. Processes. 2019; vol. 7. Hal 113-141.

[3] Nemati A., Nami H., Ranjbar F., Yari M. A comparative thermodynamic analysis of ORC and Kalina cycle for waste heat recovery: a case study for CGAM cogeneration system. Case Study Therm. Eng. 2017; vol. 9. Hal. 113.

[4] Wu Z., Pan D., Gao N., Zhu T., Xie F. Experimental testing and numerical simulation of scroll expander in a small scale organic Rankine cycle system. Appl. Therm Eng. 2015; vol. 87. Hal. 529-537.

[5] Li M., Wang J., He W., Gao L., Wang B., Ma S. Construction and preliminary test of a low-temperature regenerative Organic Rankine Cycle (ORC) using R123. Renewable energy. 2013; vol 57. Hal. 216-222.

[6] Kang S.H. Design and experimental study of ORC (organic Rankine cycle) and radial turbine using R245fa 
working fluid. Energy. 2012; vol. 41. Hal. 514-524.

[7] Zhang Y.Q., Wu Y.T., Xia G.D., Ma C.F., Ji W.N., Liu S.W. Development and experimental study on organic Rankine cycle system with single-screw expander for waste heat recovery from exhaust of diesel engine. Energy. 2014; vol. 77. Hal. 499-508.

[8] Zheng N., Zhao L., Wang X.D., Tan Y.T. Experimental verification of a rolling-piston expander that applied for low-temperature organic Rankine cycle. Appl. Energy. 2013; vol. 112. Hal. 1265-1274.

[9] Quoilin S., Lemort V., Lebrun J. Experimental study and modeling of an Organic Rankine Cycle using scroll expander. Appl Energy. 2010; vol. 87(4). Hal. 1260-1268.

[10] Pu W.H., Yue C., Han D., He W., Liu X., Zhang Q. Experimental study on Organic Rankine cycle for low grade thermal energy recovery. Appl Therm Eng. 2016; vol. 94. Hal. 221-227.

[11] Guillaume L., Legros A., Desideri A., Lemort V. Performance of a radial-inflow turbine integrated in an ORC system and designed for a WHR on truck application: an experimental comparison between R245fa and R1233zd. Appl Energy. 2017; vol. 168. Hal. 408-4022.

[12] Hu K.Y., Zhu J., Zhang W., Liu K.T., Lu X.L. Effects of evaporator superheat on system operation stability of an Organic Rankine Cycle. Appl Therm Eng. 2017; vol. 111. Hal. 793-801.

[13] Ziviani D., Gusev S., Lecompte S., Groll E.A., Braun J.E., Horton W.T. Characterizing the performance of a single-screw expander in a small-scale organic Rankine cycle for waste heat recovery. Appl Energy. 2016 ; vol. 181. Hal. 155-170.

[14] Sung T., Yun E., Kim H.D., Yoon S.Y., Choi B.S., Kim K. Performance characteristics of a 200-kW organic Rankine cycle system in a steel processing plant. Appl Energy. 2016; vol. 183. Hal. 623-635. 